\title{
TRÊS RAZÕES PARA OBEDECER, SEGUNDO THOMAS HOBBES
}

Felipe Moralles e Moraes ${ }^{1}$

Resumo: Este artigo apresenta três interpretações conflitantes sobre o modo de justificação do dever de obediência no Leviatã de Thomas Hobbes. Estas interpretações resultam em diferentes compreensões acerca dos conceitos hobbesianos de conhecimento, estado de natureza e lei de natureza. A intenção do artigo é mostrar as deficiências das assim chamadas interpretações científica e moral, a fim de defender a interpretação de uma justificação crítica e recursiva do dever de obediência. Palavras-chave: Hobbes - obediência - conhecimento - estado de natureza - lei de natureza.

\section{INTRODUÇÃO}

Thomas Hobbes aclamava-se o fundador da filosofia política, a qual "nem Platão, nem nenhum outro filósofo até agora colocou em ordem, e suficientemente ou com probabilidade provou todos os teoremas da doutrina moral, a partir dos quais os homens podem aprender como governar e como obedecer". ${ }^{2}$ Porém, os intérpretes consideram diferentemente como pretendia colocar a matéria em ordem e justificar o dever de obediência. Estão de acordo que seu objetivo central era evitar a guerra civil. Na primeira página da Introdução, na famosa comparação entre o corpo humano e o corpo político, a sedição é identificada com a doença; a guerra civil, com a morte. A pior coisa que pode ocorrer é a guerra civil. ${ }^{3} \mathrm{Nem}$ a natureza, nem uma concepção do bem, nem a graça divina

\footnotetext{
${ }^{1}$ Doutorando em filosofia política pelo Programa de Pós-Graduação em Filosofia da Universidade Federal de Santa Catarina (UFSC). E-mail: felipe.moralles@gmail.com.

${ }^{2}$ HOBBES. Leviathan, XXXI, p. 194. As traduções utilizadas neste artigo são livres e o número da página referese à edição original.

${ }^{3}$ HOBBES. Leviathan, XVIII, p. 94.
} 
unem as pessoas politicamente. As pessoas discordam radicalmente sobre o summum bonum, embora haja certamente um summum malum, que é a vida miserável e a morte violenta provocadas pela guerra civil. Teoricamente, divergem os intérpretes sobre o significado dos conceitos que justificam a coexistência de pessoas com opiniões contrárias sem se destruírem uns aos outros. Minha intenção neste trabalho é apresentar os conceitos de (i) conbecimento, (ii) estado de naturez̧a e (iii) lei de natureza sob o ponto de vista de três interpretações conflitantes sobre a justificação hobbesiana do dever de obediência, que denomino científica, moral e crítica. Em lugar de uma justificação materialista ou moral, defendo que Hobbes justifica o dever de obediência ao soberano recursivamente, como uma condição de possibilidade da ciência e da moral.

\section{A TESE CIENTÍFICA}

Em sua Teoria Política do Individualismo Possessivo, C. B. Macpherson defende que a conclamação de fundador da ciência política justificava-se por uma concepção original de filosofia sistemática, construída a partir dos elementos mais simples, recompostos lógica e dedutivamente. ${ }^{4}$ Todo o aparato conceitual de "estado de natureza", "direitos naturais", "lei de natureza" e "contrato social" podia ser explicado como uma influência da filosofia da época; mas que a justificação do dever de obediência prescindiria desses conceitos. ${ }^{5} \mathrm{~A}$ interpretação é reproduzida em sua introdução à edição inglesa do Leviathan. ${ }^{6}$ Do que Hobbes não dispensaria é, ao lado dessa reconstrução da filosofia política a partir dos elementos mais simples, de generalizações do comportamento dos indivíduos da sociedade que alvorecia na época, a partir das quais justificava a existência de um poder soberano. Junto com postulados mecanicistas (de indivíduos dissociados da sociedade política e participantes de um mercado competitivo), traz um postulado social (de indivíduos com desejos ilimitados de poder). Em célebre tese, Macpherson propõe que o liberalismo moderno estaria impregnado dessa qualidade possessiva - herdada, entre outros, de Hobbes -, de indivíduos como possuidores de capacidades, pelos quais nada devem à sociedade. A sociedade política liberal serve, então, como proteção de um sistema de trocas individuais dessas capacidades.

O primeiro postulado do sistema hobbesiano é mecanicista: "movimento não produz nada mais que movimento". ${ }^{8}$ Os seres humanos podem ser explicados como um sistema de órgãos sensitivos, nervos, músculos, imaginação, memória e razão, afetado pelo impacto de corpos externos. As ações humanas resultam do movimento de objetos externos ou da reação a impactos imaginários de objetos externos, associado ao desejo de continuar o movimento e afastar o que impeça o movimento: "a vida mesmo não é outra coisa que movimento". 'A formação de um corpo político não teria outro fundamento que o impulso de manutenção e maximização do movimento dos indivíduos. ${ }^{10}$ Nisso identifica Macpherson

\footnotetext{
${ }^{4}$ MACPHERSON. Individualismo possessivo, p. 41.

${ }^{5}$ MACPHERSON. Individualismo possessivo, p. 277.

${ }^{6}$ MACPHERSON. Introduction, p. 19 e 40.

${ }^{7}$ MACPHERSON. Individualismo possessivo, p. 15.

${ }^{8}$ HOBBES. Leviathan, I, p. 2

${ }^{9}$ HOBBES. Leviathan, VI, p. 29.

10 MACPHERSON. Introduction, p. 27-9.
} 
o primeiro elemento da teoria do individualismo possessivo: um indivíduo abstraído da sociedade política. ${ }^{11}$

É ilustrativo o conceito de poder, que o filósofo de Malmesbury define, primeiramente, como os "meios presentes para obter um bem aparente futuro". ${ }^{12}$ Ele pode ser natural (as faculdades do corpo ou do espírito) ou instrumental (riqueza, reputação, amizades, que acrescem as faculdades do corpo ou do espírito). Todos indivíduos procuram possuir algum poder, como meio de obtenção de desejos futuros, embora não necessariamente mais poder do que outros ou mais do que já têm. As primeiras causas de querela decorreriam simplesmente do desejo individual de viver bem: "plantar, semear, construir um abrigo conveniente". ${ }^{13}$ Até esse ponto o desejo de poder parece inofensivo ou, ao menos, neutro. ${ }^{14}$

Entretanto, Hobbes complementa o conceito de poder no sentido de que o natural é "a eminência das faculdades do corpo, ou da mente; a força extraordinária, forma, prudência...”. Também as formas de poder adquirido são descritas como forças defensivas ou ofensivas contra os outros. ${ }^{15}$ Não se trata, portanto, de uma medida absoluta, mas comparativa. ${ }^{16}$ Forma-se, em razão disso, um mercado de poder: "o valor... de um homem é, como de todas outras coisas, seu preço; quer dizer, tanto seria dado para o uso de seu poder; e consequentemente não é absoluto. Mas uma coisa dependente da necessidade e julgamento de outro". ${ }^{17}$ Falar em valor ou preço do indivíduo é supor cada um como vendedor ou comprador do poder de outros. Nesse mercado, "o poder de um indivíduo é tratado como mercadoria, para transações regulares nas quais são estabelecidos os preços de mercado". ${ }^{18}$ Eis o segundo elemento da teoria do individualismo possessivo: um mercado competitivo, em que cada indivíduo é uma coisa oferecida competitivamente para troca. ${ }^{19}$

Todavia, compreende o intérprete canadense que esse postulado da natureza humana não é puramente mecanicista, mas social. ${ }^{20} \mathrm{O}$ poder de cada um impede ou restringe os efeitos do poder dos demais porque os indivíduos se comparam: "se todas as coisas fossem iguais em todos os homens, nada seria estimado". ${ }^{21} \mathrm{E}$ alguns indivíduos "tomam prazer em contemplar seu próprio poder em atos de conquista que perseguem mais além do que sua segurança requer". ${ }^{22}$ Segundo Macpherson, há nisso uma generalização da sociedade burguesa e mercantil, em que alguns desejos não têm limites e algumas pessoas buscam converter os poderes naturais dos outros para seu próprio uso. ${ }^{23} E$ é esse postulado que arrastaria todos para uma corrida por acumulação de poder, em que alguém "não pode assegurar o poder e os meios de viver bem que ele possui no presente sem a aquisição de

\footnotetext{
${ }^{11}$ MACPHERSON. Individualismo possessivo, p. 29.

12 HOBBES. Leviathan, X, p. 41.

13 HOBBES. Leviathan, XIII, p. 61.

${ }^{14}$ MACPHERSON. Introduction, p. 33-6.

${ }^{15}$ HOBBES. Leviathan, X, p. 41.

${ }^{16}$ MACPHERSON. Individualismo possessivo, p. 46.

${ }^{17}$ HOBBES. Leviathan, X, p. 42.

18 MACPHERSON. Individualismo possessivo, p. 48.

${ }^{19}$ MACPHERSON. Individualismo possessivo, p. 50-1.

20 MACPHERSON. Individualismo possessivo, p. 51.

${ }^{21}$ HOBBES. Leviathan, VIII, p. 32.

22 HOBBES. Leviathan, XIII, p. 61.

${ }^{23}$ MACPHERSON. Individualismo possessivo, p. 57 e 69.
} 
mais". ${ }^{24}$ Se todos os desejos fossem limitados, seria possível alguma acomodação entre sua satisfação e a do resto das pessoas, em algum nível moderado de satisfação. Porém, na medida em que alguns têm desejo de dominar os outros, isso obriga esses últimos a sempre levar em conta a possibilidade de se defrontarem com os primeiros: todos, os com desejos moderados não menos do que os com desejos imoderados, são empurrados à luta competitiva e constante por poder sobre os outros, ou ao menos à conservação de seus poderes contra o domínio dos outros. Porque alguns desejos são ilimitados, as outras pessoas são movidas a resistir à transferência de seus poderes e, para poder resistir, lutar por mais poder. ${ }^{25} \mathrm{O}$ terceiro e decisivo postulado da teoria do individualismo possessivo consiste, portanto, nesse desejo de alguns indivíduos de ter mais poder que outros. ${ }^{26}$

A força desintegrativa da luta por mais e mais poder conduziria a repetidos colapsos e recursos à violência. $\mathrm{O}$ aumento do perigo de morte violenta mostraria a necessidade das pessoas de entregar a um soberano todo poder necessário para sua prevenção. Esse passo é introduzido por uma abstração lógica, que é o "estado de natureza". Ele consiste na suposição da inexistência de poder comum, a fim de mostrar como são as paixões dos indivíduos e sua tendência a uma vida "solitária, pobre; desprezível; brutal e curta". O estado de natureza é, nas palavras de Hobbes, "uma inferência feita das paixões" 27 , isto é, uma condição hipotética na qual os indivíduos se encontrariam inevitavelmente, como são agora, com naturezas formadas na sociedade moderna, se não existisse poder comum. ${ }^{28}$ Ele demonstra que, no estado da sociedade moderna, uma vida conforme a natureza necessariamente não será bem-aventurada.

Não obstante, os direitos naturais e as leis de natureza, assim como os desdobramentos da teoria, prescindem desse estado hipotético. ${ }^{29} \mathrm{O}$ direito natural é definido como "a liberdade que cada homem tem de usar seu próprio poder como ele mesmo quiser para a preservação de sua própria natureza; o que é dizer, da sua própria vida; e consequentemente de fazer qualquer coisa que em seu próprio julgamento e razão pode conceber ser os meios mais aptos para isso" ${ }^{30}$ O direito natural decorre do próprio impulso individual, independentemente de estar ou não no estado de natureza. ${ }^{31}$ Similarmente, a primeira lei de natureza: "um preceito, ou regra geral, descoberta pela razão, pela qual cada homem é proibido de fazer aquilo que é destrutivo da sua vida ou de retirar os meios de preservá-la; e de omitir aquilo pelo qual ele pensa seria melhor preservada". ${ }^{32}$ Em outras palavras, é uma regra que qualquer pessoa razoável, dentro ou fora do estado de natureza, pode ver como necessária. ${ }^{33}$ As leis de natureza são teoremas racionais ou prudenciais que conduzem à satisfação ótima dos desejos e estão na base do dever de obedecer ao soberano.

\footnotetext{
${ }^{24}$ HOBBES. Leviathan, XI, p. 47.

${ }^{25}$ MACPHERSON. Introduction, p. 36-7.

26 MACPHERSON. Individualismo possessivo, p. 70.

${ }^{27}$ HOBBES. Leviathan, XIII, p. 62.

${ }^{28}$ MACPHERSON. Individualismo possessivo, p. 30.

${ }^{29}$ MACPHERSON. Introduction, p. 41.

${ }^{30}$ HOBBES. Leviathan, XIV, p. 64.

31 MACPHERSON. Introduction, p. 42-3.

32 HOBBES. Leviathan, XIV, p. 64.

${ }^{33}$ MACPHERSON. Introduction, p. 43.
} 
Da procura por meios melhores, expressa na primeira lei de natureza, deduz Hobbes a segunda lei: "que o homem concorde, quando outros também o façam, e tão longe para a paz e para a defesa de si mesmo ele pensa como necessário resignar esse direito a todas as coisas; e contente-se com tanta liberdade contra outros homens quanto ele permitiria a outros homens contra ele mesmo". ${ }^{34}$ A segunda lei de natureza demanda um ato concertado de renúncia concomitante aos direitos naturais. Mas não basta o acordo de renúncia, porque a decisão racional de cooperar espontaneamente existe somente em situações em que há certa segurança de que o outro também irá cooperar. Ainda que uma pessoa acredite que a outra é um cooperador racional e enxergue os benefícios a longo prazo, há o risco da falta de reciprocidade: "pois aquele que fosse modesto e tratável e cumprisse tudo que prometesse, em tal tempo e lugar onde ninguém mais o fizesse, não faria mais do que oferecer a si como presa aos outros e procurar sua certa ruína...". ${ }^{35}$ Nunca se sabe se os demais vão manter o acordo de paz, de modo que é mais racional não cooperar do que contar com a cooperação do próximo. É sempre preferível, diz Hobbes, "a antecipação, isto é, pela força ou ardill". ${ }^{36}$ Ademais, a sociedade está cheia de pessoas dispostas a buscar benefícios de curto prazo. Os seres humanos continuam sendo criaturas sequiosas por poder e retomariam seus antigos direitos sempre que vissem nisso uma vantagem imediata. ${ }^{37}$

A garantia para o cumprimento dos pactos precisa ser, por isso, a violência que se abaterá sobre quem não o fizer. A razão impõe que se transfiram os direitos para alguma pessoa ou corpo que mantenha o acordo efetivo e use todas as forças necessárias para isso. Pessoas racionais chegariam à conclusão de que precisariam não só desistir de seu direito a tudo, mas também transferi-lo a alguma autoridade. ${ }^{38} \mathrm{Em}$ especial, seria preciso deixar ao soberano a decisão de quanto do poder seria necessário, do contrário, não teriam segurança se o poder seria suficiente para fazer valer o pacto e manter a paz. ${ }^{39}$ Dessa forma, tomando como pressuposto o autointeresse dos indivíduos em uma sociedade de mercado possessivo, Hobbes teria justificado validamente a obrigação de constituir um poder todo poderoso. ${ }^{40}$

Nesse passo, ainda que Hobbes extraia conclusões não-liberais, descreve os deveres do soberano como típicos de um Estado burguês. A necessidade de paz e ordem é a exigência mais urgente em uma sociedade de mercado. ${ }^{41}$ A justiça baseia-se unicamente no valor de mercado. ${ }^{42}$ A tarefa do soberano é garantir a segurança das pessoas, não só a preservação da vida, "mas todos os demais contentamentos que os homens, por indústria lícita, sem perigo ou ferimento ao bem público, possa adquirir para si mesmo". ${ }^{43} \mathrm{Em}$ suma, conclui Macpherson: "o Estado soberano que ele justificou é um Estado burguês". ${ }^{44}$

\footnotetext{
${ }^{34}$ HOBBES. Leviathan, XIV, p. 64-5.

${ }^{35}$ HOBBES. Leviathan, XV, p. 79.

${ }^{36}$ HOBBES. Leviathan, XIII, p. 61.

${ }^{37}$ MACPHERSON. Introduction, p. 45-6.

38 MACPHERSON. Introduction, p. 43-4.

39 HOBBES. Leviathan, XVIII, p. 89-90.

${ }^{40}$ MACPHERSON. Individualismo possessivo, p. 83 e 109.

${ }^{41}$ MACPHERSON. Individualismo possessivo, p. 113.

${ }^{42}$ MACPHERSON. Individualismo possessivo, p. 73-4.

${ }^{43}$ HOBBES. Leviathan, XXX, p. 175.

${ }^{44}$ MACPHERSON. Introduction, p. 51.
} 
A tese, por assim dizer, científica é de uma teoria que pretendia fundar o poder político (i) em pressupostos mecanicistas da ação humana, sobre os quais baseia (ii) uma situação hipotética de guerra de todos contra todos e (iii) teoremas racionais para a satisfação ótima dos desejos. Hobbes justificaria o poder soberano a partir de pressupostos mecanicistas e generalizações sobre a sociedade burguesa.

Acontece que os intérpretes que enxergam Hobbes numa tentativa de fundar a filosofia política em axiomas mecanicistas acabam geralmente concordando que as deduções dependem de elementos completamente estranhos a esses axiomas. ${ }^{45} \mathrm{~A}$ lacuna entre os princípios científicos e as generalizações sobre o ser humano e sobre a sociedade motivou, por isso, interpretações no sentido de que o fundamento filosófico para o dever de obediência é antes moral do que científico.

\section{A TESE MORAL}

Inicialmente, a interpretação moral vinculou-se à tese de uma filosofia deontológica cristã, como sustentaram A. E. Taylor e H. Warrender. As leis naturais seriam comandos de Deus. Elas obrigariam o soberano in foro interno a não cometer pecados e iniquidades. ${ }^{46}$ Essa interpretação esbarra, no entanto, em obstáculos dificilmente superáveis, como o objetivo de Hobbes de combater as doutrinas religiosas sediciosas, de submeter a religião ao poder político e de recusar a resistência ao soberano com invocação a leis divinas. O conteúdo das leis naturais é definido racionalmente, ainda que a justificação teológica lhes sirva como um complemento: a ameaça de punição divina. Em especial, as leis naturais não implicam a renúncia do direito de agir segundo a própria vontade, de maneira que não podem ser consideradas autênticas obrigações, no conceito hobbesiano do termo. ${ }^{47}$

A tese de uma filosofia moral ganhou novo vigor com a vinculação à justificação moral do Estado burguês. Para Leo Strauss, a aclamação de fundador da filosofia política era uma tentativa de restauração dos princípios morais da política, isto é, do direito natural no interior de um realismo maquiavélico de pessoas movidas pelo autointeresse. $O$ seu propósito era divorciar o direito natural do perfectibilismo humano aristotélico. Diferente dos demais animais gregários, como abelhas e formigas, as pessoas vivem em competição contínua por honras e dignidade, o que provoca inveja, ódio e guerra. $\mathrm{O}$ erro da filosofia política tradicional estaria na assunção do ser humano como um animal racional e político por natureza. ${ }^{48}$ Se os seres humanos são movidos pela satisfação de seus desejos em vez de pela razão, como concebia a filosofia política tradicional, cabia reconhecer que a paixão mais poderosa era o medo da morte e, particularmente, o medo da morte violenta nas mãos de outro. ${ }^{49}$ O desejo de autopreservação toma o lugar do summum bonum.

\footnotetext{
45 Para um apanhado, of. GREENLEAF. Hobbes: o problema da interpretação, p. 53.

46 TAYLOR. The ethical doctrine of Hobbes, p. 411, 414-5, 418; WARRENDER. The political philosophy of Hobbes, p. 7, 54-8, 159-76.

${ }^{47}$ Para uma discussão pormenorizada sobre as teses de Taylor e Warrender, cf. BRODANI. Ética e política em Hobbes, p. 154-211.

48 STRAUSS. Natural right and history, p. 169.

${ }^{49}$ STRAUSS. Natural right and history, p. 179-80.
} 
Sendo o desejo de autopreservação a única raiz possível de toda moralidade, o fato moral fundamental deixa de ser um dever do indivíduo diante do melhor regime político, para se tornar um direito "que não pode ser deposto". ${ }^{50}$ Segundo Strauss, portanto, Hobbes pretendia refundar as doutrinas de direito natural - o que fez, na trilha de Maquiavel, abandonando a discussão sobre o regime político mais condutivo à prática da virtude e deslocando a justificação dos princípios morais da política para um direito individual de autopreservação. "Uma vez - escreve o intérprete - que o fato moral fundamental e absoluto é um direito e não um dever, a função e os limites da sociedade civil devem ser definidos em termos de direito natural do homem e não em termos de seu dever natural. O Estado tem a função, não de produzir ou promover a vida virtuosa, mas de salvaguardar o direito natural de cada um". ${ }^{51}$ Há "alguns direitos que ninguém pode ser entendido por qualquer palavra ou sinal como tendo abandonado ou transferido". ${ }^{52} \mathrm{O}$ direito subjetivo toma o lugar do bom.

Enquanto doutrina que considera os direitos individuais como fato político fundamental; e a salvaguarda desses direitos individuais, como a função do Estado, chama Hobbes de o fundador do liberalismo. ${ }^{53} \mathrm{O}$ estado de natureza torna-se um tópico essencial da filosofia política, enquanto estado que fundamenta a sociedade política e faz inteligível a primazia dos direitos sobre os deveres: nele há direitos perfeitos, não deveres perfeitos. Não há mais uma tensão entre sociedade civil e natural, porque no estado de natureza já se encontram os conflitos de interesses e os desejos elementares que caracterizam a sociedade civil. ${ }^{54}$ Se cada um deseja sua autopreservação, permanece sendo naturalmente o juiz dos meios mais apropriados para a satisfação desse desejo fundamental. O consentimento precede à razão. A vontade é o núcleo da soberania. Se houver um soberano, não será por causa da sabedoria, mas por causa de um pacto social. ${ }^{55} \mathrm{~A}$ justiça deixa de ser justificada com base em padrões independentes da vontade humana; as obrigações de justiça vêm do acordo dos contratantes. ${ }^{56}$

Acompanhando essa interpretação, Pierre Manent repete que o filósofo de Malmesbury inaugurou a linguagem e valor primeiro do liberalismo: o direito individual. E acrescenta que, com estado de natureza e consentimento, inaugura outra categoria fundamental do pensamento liberal: a representação política. O poder político, enquanto produto artificial, deve ser instrumental e representar a vontade dos indivíduos, mais especificamente, a vontade deles de viverem em paz, para a qual a submissão ao soberano absoluto é um instrumento necessário. A vontade do soberano passa a ser vista, assim, no final das contas, como sua própria vontade. ${ }^{57}$

A questão é que os seres humanos, em sua estupidez, nem sempre percebem, pela crença em "poderes invisíveis", isto é, pelas crenças religiosas, o medo da morte violenta como sua paixão mais poderosa. Em razão disso, não são capazes de fundar o poder

\footnotetext{
${ }^{50}$ HOBBES. Leviathan, XIV, p. 66.

51 STRAUSS. Natural right and history, p. 181.

52 HOBBES. Leviathan, XIV, p. 66.

53 STRAUSS. Natural right and history, p. 181-2.

54 STRAUSS. Natural right and history, p. 184-5.

${ }^{55}$ HOBBES. Leviathan, XIV, p. 66.

${ }^{56}$ STRAUSS. Natural right and history, p. 186-7.

${ }^{57}$ MANENT. An intellectual history of liberalism, p. 25-7.
} 
soberano, baseado na "reta razão" ${ }^{58}$ Os principais adversários são os fanáticos, os visionários e falsos profetas, que confundem suas fantasias com verdades reveladas por Deus. Tal é a importância do conflito entre as ordens temporais e divinas (e a guerra civil inglesa que vivenciava era também uma guerra religiosa) que empenha metade do Leviathan a uma exegese biblica para defender a inexistência de leis acima do Estado. É preciso iluminar o autointeresse das pessoas, enfraquecendo ou, melhor, eliminando o medo desses poderes invisíveis. O poder de decidir sobre as coisas espirituais cabe exclusivamente ao Estado. Daí a importância do Leviathan, cuja função seria o esclarecimento das pessoas sobre sua real natureza, sobre suas reais paixões, sobre seus reais direitos, sem o que o poder soberano acabaria por malograr..$^{59}$ É o que conclama a Introdução da obra: as pessoas não são ruins? Lête a ti mesmo!

Noutra versão, menos pretensiosa e desvinculada de uma defesa do Estado burguês, Norberto Bobbio filia-se à tese da fundamentação moral da obediência ao direito positivo. A pretensão era de um sistema político tão válido como a geometria; "mas, para dar validade absoluta ao sistema, havia apenas um único caminho: colocá-lo no pedestal das leis naturais". Embora as leis naturais sejam descritas como teoremas científicos, a redução não é completa, servindo como ponto de apoio moral ao dever de obediência. ${ }^{60}$ Bobbio visualiza a filosofia moral não necessariamente do Estado burguês, mas do Estado moderno. As leis naturais são um expediente eficaz para dar fundamento aceitável à supremacia incontrastável do direito positivo. ${ }^{61}$ Não há verdadeiro conteúdo na lei natural. Elas são tão indeterminadas que se tornam inaplicáveis na prática. ${ }^{62}$ Mesmo quando invocadas diante das lacunas do direito positivo, seriam determinadas e manipuladas pelo juiz, um órgão do Estado. ${ }^{63}$ As leis naturais não vigoram no estado civil, apenas valem na fase de transição do estado de natureza. ${ }^{64}$ Desse modo, não impõem mais do que o caráter irrevogável (obediência ao pacto social); absoluto (pacto de sujeição a um terceiro acima dos associados); e indivisível (o terceiro é uma única pessoa) do poder soberano. O jusnaturalismo hobbesiano serve para justificar moralmente o Estado absoluto moderno. ${ }^{65}$

Bobbio nega, pois, que filósofo de Malmesbury fosse um precursor seja do Estado burguês, seja do liberalismo. Como todos conservadores, tinha a convicção de que a sociedade só poderia se sustentar sobre a desigualdade entre soberano e súditos, entre o que tem direito de mandar e o que têm apenas o dever de obedecer. Os homens nasceram iguais, mas devem tornar-se desiguais se desejam sobreviver. ${ }^{66}$ A definição de liberdade como ausência de interferência, de usar seu próprio poder como quiser e de não ser impedido, era um desafio aos republicanos da época, que defendiam a igualdade entre soberano e súditos. ${ }^{67}$

\footnotetext{
${ }^{58}$ HOBBES. Leviathan, II, p. 7.

${ }^{59}$ STRAUSS. Natural right and history, p. 198-200.

${ }^{60}$ BOBBIO. Thomas Hobbes, p. 125-6.

${ }^{61}$ BOBBIO. Thomas Hobbes, p. 108.

62 BOBBIO. Thomas Hobbes, p. 115.

${ }^{63}$ BOBBIO. Thomas Hobbes, p. 119.

${ }^{64}$ BOBBIO. Thomas Hobbes, p. 123.

${ }^{65}$ BOBBIO. Thomas Hobbes, p. 57.

${ }^{66}$ BOBBIO. Thomas Hobbes, p. 62.

${ }^{67}$ PETTIT. Republicanism, p. 37-8.
} 
Pouco importa se a obediência é devida às leis de Luca ou ao despotismo de Constantinopla, dizia Hobbes: a falta de liberdade é a mesma. ${ }^{68}$ Pouco importa se a invasão da liberdade seja arbitrária ou não, em nenhum caso o cidadão seria mais livre numa república do que num regime absolutista: em ambos haveria a mesma coerção. Até o direito do súdito condenado à morte não passa de um direito de escapar pela força à imposição, ou seja, um retorno ao estado de natureza que não obriga o soberano, continua Bobbio. ${ }^{69}$ A única causa de rompimento do dever de obediência "não é o abuso, e sim o não-uso, não é o excesso, e sim a escassez de poder". ${ }^{70} \mathrm{O}$ primeiro direito do soberano é não aceitar as transferências de poder para outra pessoa ou assembleia, nem o retorno ao caos da multidão. ${ }^{71}$

Nesse sentido, Gérard Lebrun acrescenta que o paralelo do modelo hobbesiano de Estado está mais próximo das democracias modernas do que do liberalismo. A única finalidade de garantir segurança está muito aquém de uma garantia da propriedade, porque somente uma lei civil arbitrária daria sentido à repartição entre aquilo que é "meu” e o que é "teu" "72; de uma garantia ao comércio exterior, estritamente regulamentado; dos contratos, delimitados pelo soberano ${ }^{73}$. Assim, entende Lebrun, o imperativo de segurança não equivale ao de um Estado burguês, mas, em uma visão bastante perspicaz, ao de um Estado social. As pessoas tendem a obedecer ao poder soberano, escreve Hobbes, pelo "desejo de comodidade e de deleite sensual". ${ }^{74}$ Assim, as pessoas "voltam-se hoje para as seguranças (no emprego, de moradia, na velhice, etc.) e não para um aprimoramento das liberdades individuais... Reclamar mais segurança do Estado, é reclamar mais leis - e toda lei civil, como Hobbes vira, não pode senão limitar um pouco mais a 'liberdade natural' dos cidadãos". ${ }^{75} \mathrm{O}$ modelo de Estado concebido não se limitava à segurança do burguês, porque todas as classes têm a possibilidade de exigir garantia política das seguranças que lhes interessam. ${ }^{76}$

A tese moral é, em suma, de uma teoria que pretendia (iii) refundar o direito natural sem pressupor a natureza política do ser humano, baseada numa (ii) situação pré-política fundamental e no (i) esclarecimento da natureza autointeressada dos indivíduos. A filosofia política de Hobbes justificaria o poder soberano com base em um direito subjetivo ou paixão natural primeira dos indivíduos.

No entanto, ambas as teses anteriores estão baseadas num modelo de passagem (mecanicista, sociológica ou moral) do estado de natureza para o estado civil e se sujeitam a uma lacuna na argumentação identificada por Jean Hampton. ${ }^{77}$ A instalação do poder soberano depende de uma autorização individual em seu favor: que cada um desista de seus poderes de dirigir a própria vida segundo a própria vontade. As ideias de autorização e de direitos são abstratas: o que as pessoas realmente fazem para pôr o soberano em posição de

\footnotetext{
${ }^{68}$ HOBBES. Leviathan, XXI, p. 110.

${ }^{69}$ BOBBIO. Thomas Hobbes, p. 123.

${ }^{70}$ BOBBIO. Thomas Hobbes, p. 51.

${ }^{71}$ HOBBES. Leviathan, XVIII, p. 88.

72 HOBBES. Leviathan, XIII, p. 63.

${ }^{73}$ HOBBES. Leviathan, XXIV, p. 129-30.

${ }^{74}$ HOBBES. Leviathan, XI, p. 48.

${ }^{75}$ LEBRUN. Hobbes aquém do liberalismo, p. 251.

${ }^{76}$ LEBRUN. Hobbes aquém do liberalismo, p. 252.

${ }^{77}$ HAMPTON. Political philosophy, p. 48.
} 
autoridade e para permitir que capture e puna quem desobedeça aos comandos é fornecerlhe força e bens o suficiente, afinal, diz Hobbes, "a obrigação dos sujeitos ao soberano é compreendida durar enquanto e não mais que o poder dure, pelo qual ele está apto a os proteger..." ${ }^{78}$ Agora, transferir toda força e todos bens a fim de resistir àquele que pode violar o acordo não é mais do que assumir a obrigação de obedecer tudo o que o soberano ordenar. As pessoas não alienam racionalmente nada mais do que a própria obediência. Mas todos estão sempre dispostos a mobilizar seus bens e a levantar novamente seus direitos se entenderem que o soberano não confere segurança suficiente: o vínculo racional com o soberano pode ser conservado pelo perigo, não pela dificuldade de o quebrar. ${ }^{79}$ Assim, conclui Hampton, que o pacto real do Leviathan precisa assumir que "quando as pessoas criam o regulador, fazem isso de modo que torne possível para eles rescindir sua concessão de autoridade e poder se eles acreditarem que o regulador não está governando de um modo que avançaria seus interesses em segurança e proteção" ${ }^{80}$ Isso significa que as pessoas nunca deporão racionalmente direitos e armas, pois, se o fizerem não terão a certeza de que os outros também o farão e de que o governo garantirá efetivamente sua segurança.

\section{A TESE CRÍTICA}

Em vez de uma tentativa de aplicação do método científico na análise política ou de refundação do direito moral, Michael Oakeshott visualiza no Leviathan o ensaio da separação entre ciências naturais e filosofia política. As proposições de Hobbes partem das sensações e da adição e subtração de nomes às sensações, não do movimento dos corpos. ${ }^{81} \mathrm{~A}$ investigação que lhe interessa não é a de causas empíricas e efeitos, mas a de causas hipotéticas e efeitos, isto é, das condições de possibilidade para certos efeitos. Para Oakeshott, a teoria política de Hobbes inaugura antes uma nova concepção de filosofia do que uma nova concepção de mundo - seja cientificista, seja liberal. À filosofia política caberia mostrar as condições racionais necessárias para a associação civil. ${ }^{82}$

Avançando uma interpretação alternativa às tradicionais, Lebrun esclarece, em seu estudo sobre o nominalismo hobbesiano, que não poderia haver ciência política ou moral sem um poder soberano. $\mathrm{O}$ mesmo que ocorre com a justiça, ocorre com a verdade: nem uma, nem outra têm sentido fora das convenções. ${ }^{83}$ Segundo Hobbes, a geometria era até o momento a única ciência, porque era a única a estabelecer as significações das palavras empregadas: partem da "explicação das denominações que vão utilizar" ${ }^{84} \mathrm{Na}$ ciência moral, o ponto de partida deveria ser a sensação, a única sobre a qual poderíamos estar indubitavelmente certos: "não há concepção na mente humana a qual não tenha por primeiro, total ou parcialmente, nascido nos órgãos dos sentidos". ${ }^{55}$ Pode fazer parecer, em

\footnotetext{
${ }^{78}$ HOBBES. Leviathan, XXI, p. 114.

${ }^{79}$ HOBBES. Leviathan, XXI, p. 109.

${ }^{80}$ HAMPTON. Political philosophy, p. 51.

${ }^{81}$ OAKESHOTT. Introduction to Leviathan, p. 20.

${ }^{82}$ OAKESHOTT. Introduction to Leviathan, p. 26-7.

${ }^{83}$ LEBRUN. Hobbes e a instituição da verdade, p. 301.

${ }^{84}$ HOBBES. Leviathan, IV, p. 14.

${ }^{85}$ HOBBES. Leviathan, I, p. 3.
} 
um primeiro momento, que as sensações bastariam para a comunicação moral, isto é, uma estipulação e encadeamentos exatos a partir dos dados fornecidos pelas sensações. ${ }^{86}$ Entretanto, a possibilidade de os nomes designarem sensações comuns, sem equívoco, é bastante restrita. Cada pessoa denomina bem o que lhe agrada e mal o que lhe desagrada. ${ }^{87}$ Um dá o nome de crueldade àquilo que o outro chama de justiça: "os homens julgam a maldade ou bondade de suas ações, das ações dos outros e do próprio Estado, por suas próprias paixões; ninguém chama bem ou mal outra coisa que aquilo que é assim a seus próprios olhos, sem consideração alguma para com as leis públicas". ${ }^{88}$ Por isso, a possibilidade de os nomes designarem concepções comuns fica limitada às matérias restringe Hobbes - que "não vão de encontro à ambição, ao lucro ou à cobiça de ninguém", ${ }^{89}$ Em matéria moral, a unidade de sentido das palavras é inalcançável; a universalidade intersubjetiva, inconcebível. ${ }^{90}$

Nem por isso Hobbes abandona o discurso moral sobre o justo e o injusto à autoridade que cada um admira, ou ao relativismo das paixões particulares, sob pretexto de que as disputas semânticas seriam absolutamente indecidíveis. ${ }^{91} \mathrm{Em}$ suas palavras: "o louco disse em seu coração que não há tal coisa como Justiça... porque, onde não há segurança de performance em qualquer lado, a questão não é de promessas mútuas". ${ }^{92}$ As doutrinas filosóficas e morais podem ser tão verdadeiras como a geometria, se estiverem baseadas nas sensações e na fixação de nomes, cuja lembrança implica um conhecimento. Da mesma forma que a verdade depende da memória, por exemplo, da convenção da palavra "triângulo", para que não precisemos a cada vez repetir a contemplação do objeto e de suas propriedades 93 , a justiça depende da "memória da primeira constituição de seu Estado". ${ }^{44} \mathrm{O}$ conhecimento implica, em quaisquer dos casos, na ciência ou na moral, de uma lembrança das convenções.

A diferença entre verdade e justiça está em que a convenção linguística, em geral, não precisa temer a execução do pacto pelos demais, porque a falta de obediência apenas torna a comunicação impossível. ${ }^{95}$ A convenção civil implica, enquanto isso, temor à segurança pessoal:

Se tivesse alguma coisa contrária a qualquer direito de alguém à dominação, ou ao interesse de homens que têm domínio, que os três ângulos do triângulo fossem iguais a dois ângulos de um quadrado, essa doutrina seria, senão disputada, suprimida pela queima de todos os livros de geometria, tão longe aquele a que diziam respeito fosse capaz. ${ }^{96}$

\footnotetext{
${ }^{86}$ LEBRUN. Hobbes e a instituição da verdade, p. 312.

${ }^{87}$ HOBBES. Leviathan, IV, p. 17 e VI, p. 24.

${ }^{88}$ HOBBES. Leviathan, XLVI, p. 376.

${ }^{89}$ HOBBES. Leviathan, XI, p. 50.

${ }^{90}$ LEBRUN. Hobbes e a instituição da verdade, p. 313-4.

${ }^{91}$ LEBRUN. Hobbes e a instituição da verdade, p. 317-8.

${ }^{22}$ HOBBES. Leviathan, XV, p. 72.

${ }^{93}$ HOBBES. Leviathan, IV, p. 14.

${ }^{94}$ HOBBES. Leviathan, XXVI, p. 142.

${ }^{95}$ LEBRUN. Hobbes e a instituição da verdade, p. 301.

${ }^{96}$ HOBBES. Leviathan, XI, p. 50.
} 
Muitos juízos de valor são mais ou menos consensuais e, como na geometria, não carecem da referência à instituição do Estado. Porém, mesmo aquele que profere o verdadeiro jamais será por todos reconhecido como tal. Sempre que as sensações e os nomes não bastem como regra e isso gere temor aos interesses fundamentais dos indivíduos, caberá ao soberano completar o código de signos, para torná-los universais. ${ }^{97}$

O ponto é distinguir a verdade das proposições, que deveriam racionalmente contar com a adesão dos demais, das proposições que se tornaram lei pela autoridade, as quais devem necessariamente contar com a adesão dos súditos. Nos termos de John Rawls, as leis naturais contêm princípios da razoabilidade, mas que só podem ser justificados se forem, ao mesmo tempo, racionais. ${ }^{98}$ Fora da coação legal, a universalidade dos princípios permanece irrealizável. As leis naturais deixam de ser simples regras hipotéticas e passam a obrigar universalmente somente dentro de um ordenamento constituído: "só depois de instituído o Estado elas efetivamente se tornam leis, nunca antes, pois passam então a ser ordens do Estado, portanto também leis civis, pois é o poder soberano que obriga os homens a obedecer-lhes". ${ }^{99}$ A teoria política é justificada razoavelmente com base em direitos morais e em interesses sensíveis de autopreservação, mas sua realização depende racionalmente do Estado.

Com isso, é possível compreender o famoso adágio: non veritas, sed auctoritas facit legem. ${ }^{100}$ Embora somente o soberano possa fazer que os sujeitos cheguem ao entendimento mútuo, sem o qual muitas verdades não estariam em vigor, não há confusão entre verdade e autoridade. A verdade consiste "na ordenação correta de nomes em nossas afirmações". ${ }^{101}$ A autoridade, no "direito de fazer uma ação". ${ }^{102}$ À ciência cabe expor o verdadeiro, mesmo que a instituição da verdade dependa da lei e da ordem. A instituição política não é um substituto da verdade ou da moralidade, mas uma condição de possibilidade para seu funcionamento. ${ }^{103}$ No Estado, a lei civil não suprime a verdade sobre os assuntos morais, somente impede que cada um pretenda comportar-se como medida e tomar sua concepção como norma. A universalidade da moral torna-se possível na medida em que cada um abdique da sua condição de medida e da sua pretensão pessoal de legiferar sobre os temas universais. ${ }^{104}$ É a existência do soberano que torna possível, enfim, aderir racionalmente às leis de natureza e considerar injustas as leis ou atos que desestabilizam as condições necessárias à paz. ${ }^{105}$

Dentro dessa corrente interpretativa que delineia o saber político como condição de possibilidade para o saber científico e moral, Michel Foucault desenvolve a noção hobbesiana de um estado de natureza que não é nem hipotético como na interpretação mecanicista, nem

\footnotetext{
${ }^{97}$ LEBRUN. Hobbes e a instituição da verdade, p. 321.

98 RAWLS. Lectures, p. 55.

${ }^{99}$ HOBBES. Leviathan, XXVI, p. 138.

100 HOBBES. Leviathan, XXVII, p. 143.

${ }^{101}$ HOBBES. Leviathan, IV, p. 15.

102 HOBBES. Leviathan, XVI, p. 81.

${ }^{103}$ LEBRUN. Hobbes e a instituição da verdade, p. 322-3.

${ }^{104}$ LEBRUN. Hobbes e a instituição da verdade, p. 326.

${ }^{105}$ HOBBES. Leviathan, XV, p. 79.
} 
fundamental como na interpretação moral, mas premente. Hobbes supõe como primeira condição objetiva do estado de guerra a igualdade dos seres humanos. Uma desigualdade evidente entre fortes e fracos brecaria a possibilidade de guerra: "a relação de força seria fixada logo de saída por urna guerra inicial que excluiria que ela continuasse, ou então, ao contrário, essa relação de força permaneceria virtual dada a própria timidez dos fracos". ${ }^{106}$ No estado diferenças insuficientes, a aleatoriedade na relação de forças (o fraco não renuncia, o forte não é o bastante para não ficar inquieto) conserva um estado de guerra. ${ }^{107}$

A igualdade fundamental da qual Hobbes extrai os direitos e as obrigações naturais decorre do simples medo da morte, e não da igual sujeição ao mercado: "o mais fraco tem força suficiente para matar o mais forte, ou por maquinação secreta, ou se confederando com outros". ${ }^{108}$ Ninguém está imune à possibilidade de sofrer morte violenta. Dessa igualdade extrai que nenhum ser humano pode pretender para si qualquer regalia acima dos outros, ou seja, todos possuem igual expectativa de satisfação das vontades. ${ }^{109}$ E o estado natural não é necessariamente brutal, de um enfrentamento direto entre os indivíduos, com punhos, sangue e batalhas, reforça Foucault, mas um estado de incertezas e riscos. É mais um estado de guerra, ou disposição a qualquer tempo de lutar, do que uma guerra. Esse estado de guerra de todos contra todos é permanente em qualquer sociedade: não somente num Estado civilizado, em que um viajante nunca esquece de fechar com cuidado a fechadura da porta; mas também nas florestas da América, entre as tribos indígenas; entre um Estado e outro da Europa. ${ }^{110}$ De maneira concreta, "a guerra de todos contra todos, Hobbes não a situa simplesmente no nascimento do Estado - na manhã real e fictícia do Leviatã -, ele a segue, ele a vê ameaçar e manar, depois mesmo da constituição do Estado, em seus interstícios, nos limites e nas fronteiras do Estado". ${ }^{111}$ Enfim, "não é uma fase que o homem abandonaria definitivamente no dia em que nascesse o Estado; trata-se, de fato, de uma espécie de pano de fundo permanente...". ${ }^{112}$

A soberania fundamenta-se na vontade de preferir a vida à morte violenta, independente de uma renúncia geral e consentida dos poderes. Ela congloba tanto a dominação estabelecida por "instituição" na comunidade "política", quanto a dominação estabelecida por "aquisição" ou pela "força natural". O soberano por aquisição tem os mesmos direitos que o soberano por instituição. A dominação após a vitória de um Estado sobre outro - em que os vencidos aceitam obedecer, trabalhar, ceder a terra aos vencedores - não difere da dominação de uma mãe sobre a criança, que obedece aos pais porque, sem eles, não pode viver. ${ }^{113} \mathrm{O}$ que é decisivo na constituição da soberania, conclui Foucault, "não é a qualidade da vontade, nem mesmo sua forma de expressão ou seu nível...pouco importa que se esteja com a faca na garganta, pouco importa que se possa ou não formular

\footnotetext{
${ }^{106}$ FOUCAULT. Em defesa da sociedade, p. 103-4.

${ }^{107}$ FOUCAULT. Em defesa da sociedade, p. 104-5.

108 HOBBES. Leviathan, XIII, p. 60.

${ }^{109}$ HOBBES. Leviathan, XIII, p. 60-1.

${ }^{110}$ HOBBES. Leviathan, XIII, p. 63.

${ }^{111}$ FOUCAULT. Em defesa da sociedade, p. 102.

112 FOUCAULT. Em defesa da sociedade, p. 107.

${ }^{113}$ HOBBES. Leviathan, XX, p. 101-2.
} 
explicitamente a vontade". ${ }^{114}$ Não importa, em suma, que se trate de um acordo, de uma batalha, de uma relação entre pais e filhos: o que sempre encontramos por trás da soberania é a vontade de viver e o medo da morte. ${ }^{115} \mathrm{O}$ pacto extorquido pelo medo é válido, pois todo sistema político é baseado no medo. Hobbes colocou a relação de guerra no fundamento de toda relação de poder. ${ }^{116}$

Para Foucault, a teoria hobbesiana pretendia tornar o fato da guerra e da conquista real indiferente à soberania: mostrar que ela não é a gênese dos Estados, nem reconduz ao poder civil. ${ }^{117}$ Queria eliminar certo papel do saber histórico na luta política, isto é, o uso prático e retórico de guerras e invasões passadas para fundamentar a soberania. "Numa palavra - escreve o filósofo francês - o que Hobbes quer eliminar é a conquista, ou ainda a utilização, no discurso histórico e na prática política, desse problema que é o da conquista". E fazia isso dizendo que "guerra ou não guerra, derrota ou não, conquista ou acordo, é tudo a mesma coisa", é tudo o mesmo contrato baseado no medo e na vontade de viver. ${ }^{118}$ Essa prática e retórica havia surgido na conquista normanda em 1066 e no exercício do poder monárquico, desde então, em virtude do poder de conquista. Do lado dos parlamentares e da pequena-burguesia saxã, havia a necessidade de revolta contra esses supostos conquistadores e contra as leis normandas. O pano de fundo da guerra de conquista como traço permanente das relações sociais era o grande adversário de Hobbes. Ele queria eliminar do pensamento político o problema da conquista e o historicismo político, enquanto discurso de dominação histórica. ${ }^{119}$ É aclamado pai da filosofia política porque punha "o contrato atrás de toda guerra e de toda conquista e salvando assim a teoria do Estado". ${ }^{120}$

A tese crítica identifica, portanto, uma teoria que (iii) não pretendia demonstrar um modelo de passagem, mas as condições de possibilidade da moral. A gramática política serve como (i) condição para um saber universalizável. Apela, por isso, a (ii) um pano de fundo do estado de guerra, independentemente de qualquer fundamento histórico. A filosofia política de Hobbes justifica o poder soberano recursivamente, como condição de possibilidade de discursos científicos e morais com caráter universal.

\section{CONCLUSÃO}

A forma de resolver o impasse da implausibilidade da deposição dos poderes individuais é insistir - e nisso não há diferença entre as interpretações de pensadores tão diversos como Oakeshott, Foucault e Rawls -, que a situação do estado de natureza não pretende fundamentar o Estado por meio de uma racionalidade estratégica ou moral, mas o conservar da possibilidade sempre presente de esfacelamento. ${ }^{121}$ Não devemos entrar no estado de natureza, pois não há mecanismo racional de saída. A questão não é explicar como

\footnotetext{
${ }^{114}$ FOUCAULT. Em defesa da sociedade, p. 109-10.

115 HOBBES. Leviathan, XX, p. 103.

116 FOUCAULT. Em defesa da sociedade, p. 102.

${ }^{117}$ FOUCAULT. Em defesa da sociedade, p. 112.

118 FOUCAULT. Em defesa da sociedade, p. 113.

${ }^{119}$ FOUCAULT. Em defesa da sociedade, p. 132-3.

${ }^{120}$ FOUCAULT. Em defesa da sociedade, p. 114.

${ }^{121}$ RAWLS. Lectures, p. 30-2.
} 
sair do estado de natureza, mas os requisitos para não abandonar o estado civil existente e cometer um retrocesso nos interesses fundamentais de todos. ${ }^{122} \mathrm{~A}$ racionalidade do discurso científico e moral é independente, mas sua universalidade depende de um poder político instituído. É um materialismo crítico, que não justifica a obediência política de modo científico ou moral, senão recursivamente, como condição de possibilidade para a ciência e a moral. Muito tempo depois de começarem a construir "comunidades imperfeitas, e capazes de recair na desordem, podem ser descobertos princípios de raciocínio, por industriosa meditação, para tornar sua constituição (com exceção da violência externa) eterna. E tais são os que neste discurso expus...". ${ }^{123}$

\section{THREE REASONS TO OBEY, ACCORDING TO THOMAS HOBBES}

Abstract: This article presents three conflicting interpretations of Thomas Hobbes' justification of the obligation of obedience in Leviathan. These interpretations result in different understandings of the Hobbesian concepts of knowledge, state of nature, and law of nature. The intention of the article is to show the deficiencies of the so-called scientific and moral interpretations in order to defend the interpretation of a critical and recursive justification of the obligation of obedience.

Keywords: Hobbes - obedience - knowledge - state of nature - law of nature.

\section{REFERÊNCIAS BIBLIOGRÁFICAS}

BOBBIO, N. Thomas Hobbes. Trad. Carlos Nélson Coutinho. Rio de Janeiro: Campus, 1991.

BRODANI, C. Ética e politica em Hobbes. Dissertação (Mestrado em Filosofia). UFSC, Florianópolis, 2012.

FOUCAULT, M. Em defesa da sociedade: curso no Collège de France (1975-1976). Trad. Maria Ermantina Galvão. São Paulo: Martins Fontes, 2005.

GREENLEAF, W. H. Hobbes: o problema da interpretação. In: QUIRINO, Célia Galvão; SOUZA, Maria Teresa Sadek R. de (org.). O pensamento político clássico: Maquiavel, Hobbes, Locke, Montesquieu, Rousseau. São Paulo: T. A. Queiroz, 1980.

LEBRUN, G. Hobbes aquém do liberalismo. In: MOURA, Carlos Alberto Ribeiro de. [et. al.] (org.). A filosofia e sua história. São Paulo: Cosac Naify, 2006.

. Hobbes e a instituição da verdade. In: MOURA, Carlos Alberto Ribeiro de. [et. al.] (org.). A filosofia e sua história. São Paulo: Cosac Naify, 2006.

HAMPTON, J. Political philosophy. Colorado: Westview Press, 1997.

HOBBES, T. Leviathan. C. B. Macpherson (ed.). Harmondsworth: Pelican Books, 1968.

122 RAWLS. Lectures, p. 33.

${ }^{123}$ HOBBES. Leviathan, XXX, p. 176. 
MACPHERSON, C. B. A teoria politica do individualismo possessivo: de Hobbes a Locke. Trad. Nelson Dantas. Rio de Janeiro: Paz e Terra, 1979.

MANENT, P. An intellectual history of liberalism. Transl. Recebba Balinsk. Princeton: Princeton University Press, 1995.

OAKESHOTT, M. Introduction to Leviathan. In: . Hobbes on civil association. Indianapolis: Liberty Fund, 1975.

PETTIT, P. Republicanism: a theory of freedom and government. Oxford: Claredon Press, 2002.

RAWLS, J. Lectures on the history of political philosophy. Samuel Freeman (Ed.) Cambridge: Harvard University Press, 2007.

STRAUSS, L. Natural right and bistory. Chicago: University of Chicago Press, 1953.

TAYLOR, A. E. The ethical doctrine of Hobbes. Philosopby, vol. 13, n. 52, oct. 1938, p. 406-424.

WARRENDER, H. The political philosophy of Hobbes: his theory of obligation. Oxford: Clarendon Press, 1957. 